\begin{tabular}{c} 
DURNAI, R IS'T \\
(Rekayasa Sistem dan Teknologi Informasi) \\
Vol.3 No.2(2019) $106-112 \quad$ ISSN Media Elektronik: $2580-0760$ \\
\hline
\end{tabular}

\title{
Pengamanan Restful API menggunakan JWT untuk Aplikasi Sales Order
}

\author{
Edy $^{1}$, Ferdiansyah $^{2}$, Wahyu Pramusinto ${ }^{3}$, Sejati Waluyo ${ }^{4}$ \\ 1,2,3,4 Teknik Informatika, Fakultas Teknologi Informasi, Universitas Budi Luhur \\ ${ }^{1}$ flammingjr@gmail.com, ${ }^{2}$ ferdiansyah@budiluhur.ac.id, ${ }^{3}$ wahyu.pramusinto@budiluhur.ac.id, \\ ${ }^{4}$ sejati.waluyo@budiluhur.ac.id
}

\begin{abstract}
The company has an important role in attracting the attention of customers by promoting its products and services so that it can be widely known by the community through the sales division (sales person). The biggest challenge faced by companies is related to marketing, namely stable and sustainable income growth, and customer loyalty. So that the application of information and communication technology is needed in the business world as a tool to win the main competition in marketing products or services. In the company, order data made by the sales person is still via telephone. You need an application to speed up the product ordering process to customers. To solve these problems, each sales person will use a sales order application through a smartphone device that will make product orders. And product ordering data will go to a webbased application run by admin for the invoice creation process. This application is designed using the RESTful API which is one of the implementation models of the web service and. In terms of data exchange security using the Json Web Token. With this sales order application, it can simplify the sales person's performance in marketing their products. This application work runs well on the web and android device so the process of ordering products becomes easier. The use or json web token authentification on the RESTful API makes the application more secure because this application can not be accessed if it does not use tokens.
\end{abstract}

Keywords : Kata kunci: RESTFUL, API, JWT, Android, Webservice

\begin{abstract}
Abstrak
Perusahaan mempunyai peran penting didalam menarik perhatian pelanggan dengan mempromosikan produk dan layanannya sehingga dapat dikenal luas oleh masyarakat melalui divisi penjualan (sales person). Tantangan terbesar yang dihadapi oleh perusahaan sangat berkaitan dengan pemasaran, yaitu pertumbuhan pendapatan yang stabil dan berkelanjutan, serta loyalitas pelanggan. Sehingga penerapan teknologi informasi dan komunikasi diperlukan dalam dunia bisnis sebagai alat bantu memenangkan persaingan utama dalam memasarkan produk atau jasa. Di dalam perusahaan, data pemesanan yang dilakukan sales person masih melalui telephone. Dibutuhkan aplikasi untuk mempercepat proses pemesanan produk kepada pelanggan. Untuk memecahkan permasalahan tersebut, masing-masing sales person akan menggunakan aplikasi sales order melalui perangkat smartphone yang akan membuat pemesanan produk. Dan data pemesanan produk akan masuk ke aplikasi berbasis web yang dijalankan admin untuk proses pembuatan invoice. Aplikasi ini dirancang menggunakan RESTful API yang merupakan salah satu model implementasi dari web service. Keamanan dalam hal pertukaran data pada aplikasi ini menggunakan Json Web Token. Dengan adanya aplikasi sales order ini dapat mempermudah kinerja sales person dalam memasarkan produknya Aplikasi sales order ini berjalan baik pada web dan android sehingga proses pemesanan produk menjadi lebih mudah. Penggunaan autentifikasi json web token pada RESTful API ini membuat aplikasi menjadi lebih aman karena aplikasi tidak dapat diakses jika tidak menggunakan token.
\end{abstract}

Kata kunci: RESTFUL, API, JWT, Android, Webservice

(C) 2019 Jurnal RESTI

\section{Pendahuluan}

Divisi Penjualan adalah ujung tombak perusahaan yang mempunyai tugas utama untuk memasarkan produk[1]. Tanpa pemasaran yang baik maka besarnya aset perusahaan, teknologi yang canggih dan modern, dan

Diterima Redaksi : 15-04-2019 | Selesai Revisi : 20-05-2019| Diterbitkan Online : 01-08-2019 produk yang berkualitas akan kurang berarti bagi kelangsungan perusahaan dalam memaksi-malkan penjualan, perolehan laba serta dalam mengembalikan investasi. Dan tantangan terbesar yang dihadapi pemimpin perusahaan di seluruh dunia sangat berkaitan 
dengan pemasaran, yaitu pertumbuhan pendapatan yang stabil dan berkelanjutan, serta loyalitas pelanggan.

Didalam kinerja perusahaan dibidang penjualan terdapat sales-sales profesional yang diharapkan dapat menunjang kepentingan pergera-kan untuk menyusun strategi dan taktik bisnis perusahaan dengan memberikan solusi atau saran kepada pelanggan atas masalah yang dihadapi.Hal ini diharapkan dapat lebih memaksimalkan kepen-tingan dalam alur kerja dalam memasarkan produk tanpa keraguan pada pelanggan.

Kendala yang dialami perusahaan adalah kinerja sales person yang tidak maksimal dalam memasarkan produk kepada pelanggan. Data pemesanan produk masih dilakukan menggunakan telepon. Salah satu cara yang dapat dilakukan pihak manajemen perusahaan adalah membuat aplikasi sales orderberbasis mobile dan 2) webdengan menggunakan teknologi RESTful API dengan autentikasi keamanan menggunakan Json Web Token.

Tujuan pembuatan aplikasi sales order ini adalah dengan menerapkan teknologi dengan merancang suatu sistem dengan aristektur REST yang dapat digunakan oleh berbagai client seperti aplikasi mobile, aplikasi web dan aplikasi dekstop agar membantu perusahaan dari sistem yang berjalan manual diubah menjadi suatu sistem yang terkomputerisasi sehingga dapat meningkatkan efesiensi kinerja bagi perusahaan, namun dalam pengujian aplikasi hanya dilakukan berbasis web dan mobile. Dan mempermudah dan mempercepat kinerja sales person dalam memasarkan produk atau barang terhadap pelanggan.

Sehingga dapat dibuat desain rancangan layar dan desain program untuk memfasilitasi fitur-fitur yang dibutuhkan pada aplikasi sales order. Untuk implementasi desain rancangan layar menjadi tampilan form menggunakan bahasa pemograman PHP untuk berbasis web dan pada mobile smartphone menggunakan bahasa pemograman java, serta database yang terhubung menggunakan MariaDB. Dan selanjutnya dilakukan tahap testing dan pengujian program dengan menggunakan tools yaitu postman.

Web service merupakan sebuah perangkat lunak yang tidak terpengaruh oleh platform, arsitektur, maupun bahasa pemograman, yang meyediakan layanan atau method-method untuk pertukaran data yang dapat diakses oleh network. Contoh implementasi dari web service antara lain adalah SOAP dan REST. Web service memiliki empat lapisan dasar seperti pada Gambar $1[2]$.

Gambar 1 diatas menunjukkan blok bangunan web service yang mana menyediakan fasilitas komunikasi jarak jauh antara dua aplikasi yang merupakan layer arsitektur web service [3].

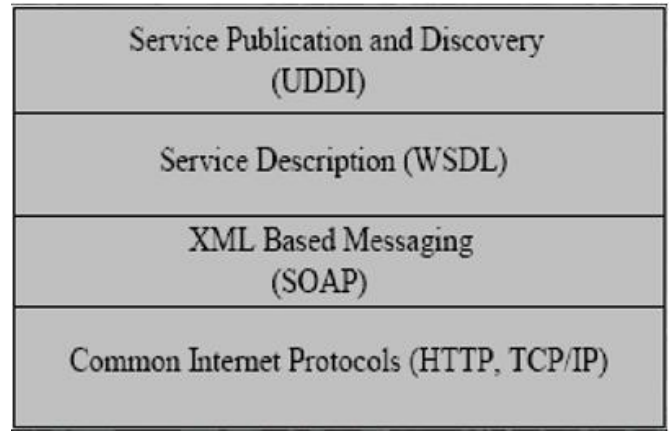

Gambar 1. Lapisan DasarWeb Service

1) Layer 1 : protokol internet standar yang digunakan sebagai sarana transportasi adalah HTTP dan TCP/IP.

2) Layer 2 :Simple Object Access Protocol (SOAP) berbasiskan $X M L$ dan digunakan untuk pertukaran informasi antar sekelompok layanan.

3) Layer 3 :Web service Definition Language (WSDL) digunakan untuk mendiskripsikan attribute layanan.

4) Layer 4 :Universal Description Discovery and Integration, yang mana merupakan direktori pusat untuk deskripsi layanan.

Salah satu jenis dari web service adalah REST atau RESTful (Representational State Transfer).REST sendiri memungkinkan system request dapat mengakses dan memanipulasi teks yang direpresentasikan dari sebuah web service.Web service API yang menggunakan REST disebut dengan RESTful API. Tidak seperti jenis web service lainnya, RESTful API tidak memiliki standar yang resmi untuk notasinya dikarenakan REST merupakan sebuah arsitektur [4].

REST menetukan sekumpulan prinsip arsitektur yang mana dapa digunakan untuk merancang web service yang berfoukus pada sumber daya sistem, termasuk bagaimana sumber daya yang dialamatkan dan ditransfer melalui HTTP oleh berbagai klien yang ditulis dalam Bahasa pemograman yang berbeda[4]. Dimana tujuannya adalah untuk menjadikan sistem memiliki performa yang baik, cepat, dan mudah untuk dikembangkan (scale) terutama dalam pertukaran dan komunikasi data.Umumnya menggunakan HTTP (Hypertext Transfer Protocol) sebagai protokol untuk komunikasi data.

Teknologi pengembangan webservice selain REST terdapat salah satu webservice yang familia bernama Simple Object Access Protocol (SOAP) dimana pada seperti halnya REST dapat melakukan pertukaran data yang sama untuk beberapa platform yang berbeda, namaun SOAP hanya terbatas pada keluaran berupa XML (Extensible Markup Language) [5]

Pada arsitektur REST, REST server menyediakan resources (sumber daya / data) dan REST client mengakses dan menampilkan resource tersebut untuk 
penggunaan selanjutnya. Setiap resource diidentifikasi SHA-256 merupakan salah satu fungsi hash satu arah, oleh URIs (Universal Resource Identifiers) atau global karena tidak mungkin menemukan pesan dari message ID. Resource tersebut direpresentasikan dalam bentuk digest yang dihasilkan.SHA-256 menggunakan enam format teks, JSON atau XML.

Json Web Token adalah sebuah token berbentuk string JSON yang sangat padat (ukurannya), informasi mandiri yang gunanya sendiri untuk melakukan sistem autentikasi dan pertukaran informasi. Karena bentuknya kecil, token JWT dapat dikirim melalui URL, parameter HTTP POST atau di dalam header HTTP, dan juga karena ukurannya yang kecil maka dapat ditransmisikan dengan lebih cepat. Disebut informasi mandiri karena isi dari token yang dihasilkan memiliki informasi dari pengguna yang dibutuhkan, sehingga tidak perlu query ke basis data lebih dari satu kali [6].

JWT bekerja dimana token ini seperti password, jadi ketika user berhasil melakukan login maka serverakan memberikan sebuah token. Nanti token tersebut akan disimpan oleh user pada local storage atau cookies browser dan bila user ingin mengakses halaman halaman tertentu maka harus menyertakan token tersebut. Untuk itu userakan mengirim balik token yang dikasih diawal tadi sebagai bukti bila user ini, sudah melakukan login.

fungsi logika, di mana setiap fungsi beroperasi pada 32bit, yang direpresentasikan sebagai $x, y$, dan $z$ [7]. Berikut adalahenam fungsi logika seperti pada persamaan :

$$
\begin{aligned}
& \operatorname{Ch}(x, y, z)=(x \wedge y) \oplus(-x \wedge z) \\
& \operatorname{Maj}(x, y, z)=(x \wedge y) \oplus(x \wedge z) \oplus(y \wedge z) \\
& \sum_{0}^{(256)}(x)=\operatorname{ROTR}^{2}(x) \oplus \operatorname{ROTR}^{13}(x) \oplus \\
& \operatorname{ROTR}^{22}(x) \\
& \sum_{1}^{(256)}(x)=\operatorname{ROTR}^{6}(x) \oplus \operatorname{ROTR}^{11}(x) \oplus \\
& \operatorname{ROTR}^{25}(x) \\
& \sigma_{0}^{(256)}(x)=\operatorname{ROTR}^{7}(x) \oplus \operatorname{ROTR}^{18}(x) \oplus \\
& \operatorname{SHR}^{3}(x) \\
& \sigma_{1}^{(256)}(x)=\operatorname{ROTR}^{17}(x) \oplus \operatorname{ROTR}^{19}(x) \oplus \\
& \operatorname{SHR}^{10}(x)
\end{aligned}
$$

Smartphone merupakan sebuah device yang memungkinkan untuk melakukan komunikasi, Struktur JWT terdiri dari tiga bagian yang dipisahkan didalamnya juga terdapat fungsi PDA (Personal Digital oleh titik (.), yaitu header, payload, dan signature.Oleh Assistant) dan berkemampuan seperti layaknya karena itu, JWT biasanya terlihat seperti berikut ini komputer. Beberapa sistem operasi yang dapat (xxxxx.yyyyy.zzzzz).

Hash adalah fungsi yang menerima masukan string yang panjangnya sembarang dan mengkonversinya menjadi string keluaran yang panjangnya tetap (fixed) umumnya berukuran jauh lebih kecil daripada ukuran string semula. Fungsi hash dapat menerima masukan stringapa saja [7].

Keyed-hash Message Authentication Code adalah teknik Message Authentication Code yang dibuat oleh Mihir Bellare, Ran Canetti, Hugo Krawczyk pada tahun 1996. Hal ini didasari karena fungsi hash itu sendiri tidak memungkinkan penggunaan kunci ketika menghitung nilai digest-nya. Tujuan dari dibangunnya algoritma HMAC ini adalah [7] Untuk menggunakan ditemukan pada smartphone antara lain, Symbian OS, iPhone OS, RIM Blackberry, Windows mobile, Linux, Palm WebOS, dan Android.Android merupakan suatu sistem operasi mobile yang berbasis pada sistem operasi Linux [8].

Android pertama kali dikembangkan oleh perusahaan startup bernama Android, Inc yang berpusat di Palo Alto, California, Amerika Serikat., yang digawangi oleh Andy Rubin, Rich Miner, Nick Sears, dan Chris White. Pada bulan Agustus 2005, Google membeli Android dan mengambil ahli proses pengembangannya hingga pada saat ini. Google merilis versi beta Android SDK (System Development Kit) pada November 2007 [8].

fungsi hash, tanpa modifikasi, yang telah tersedia dan PHP atau kependekan dari Hypertext Preprocessor mudah didapatkan. Selain itu digunakan juga untuk adalah salah satu bahasa pemrograman open source mempertahankan performa dari algoritma hash yang yang sangat cocok atau dikhususkan untuk sudah ada. Ditambah ntuk menggunakan dan mengatur pengembangan web dan dapat ditanamkan pada sebuah kunci secara mudah. Seta untuk mendapatkan skripsi HTML.Bahasa PHP dapat dikatakan pengertian yang lebih dalam dari analisis kriptografi menggambarkan beberapa bahasa pemrograman seperti mengenai kekuatan mekanisme autentikasi yang C, Java, dan Perl serta mudah untuk dipelajari.PHP berdasarkan fungsi hash sehingga nantinya digunakan merupakan bahasa scripting server - side, dimana untuk mempermudah pengubahan atau penggantian pemrosesan datanya dilakukan pada sisi server. fungsi hash yang digunakan apabila algoritma hash Sederhananya, serverlah yang akan menerjemahkan baru yang lebih cepat atau lebih aman ditemukan.

skrip program, baru kemudian hasilnya akan dikirim kepada client yang melakukan permintaan [9].

Jurnal RESTI (Rekayasa Sistem dan Teknologi Informasi) Vol. 3 No. 2 (2019) 106 - 112 
Pada prinsipnya serverakan bekerja apabila ada Secara umum aplikasi yang akan dibuat terdiri dari dua permintaan dari client. Dalam hal ini client bagian besar yaitu aplikasi yang ada pada bagian client menggunakan kode-kode PHP untuk mengirimkan dan aplikasi yang ada pada bagian server. Aplikasi permintaan ke server.Dalam hal ini client yang ada di server bertugas untuk menyediakan data menggunakan kode-kode PHP untuk mengirimkan yang dapat dikonsumsi oleh aplikasi client.Sedangkan permintaan ke server.Sistem kerja dari PHP diawali aplikasi client digunakan untuk meminta data dari dengan permintaan yang berasal dari halaman website aplikasi yang ada di server.

oleh browser. Berdasarkan URL atau alamat website dalam jaringan internet, browserakan menemukan sebuah alamat dari webserver, mengidentifikasi halaman yang dikehendaki, dan menyampaikan segala informasi yang dibutuhkan oleh webserver.

Database Management System (DBMS) merupakan perangkat lunak untuk mengendalikan pembuatan, pemeliharaan, pengolahan, dan penggunaan data yang berskala besar.Penggunaan DBMS saat ini merupakan hal yang sangat penting dalam segala aspek, baik itu dalam skala yang besar atau kecil.Beberapa DBMS yang digunakan adalah MySQL dan MariaDB.MariaDB merupakan salah satu database server yang digunakan untuk menyimpan dan memanajemen data.MariaDB tidak jauh berbeda dengan MySQL, karena MariaDB merupakan versi pengembangan terbuka dan mandiri dari MySQL.Sejak diakuisisinya MySQL oleh Oracle pada September 2010, Monty Program sebagai penulis awal kode sumber MySQL memisahkan diri dari pengembangan dan membuat versi yang lebih mandiri yakni MariaDB [10].

\section{Metode Penelitian}

Metode dalam pengembangan penelitian yang digunakan adalah metode waterfall dimana tahap awal metode ini adalah melakukan Analisis yakni dimana cara yang digunakan adalah melalui wawancara dengan beberapa karyawan. Setelah didapatkan data yang dibuthkan, tahap selanjutnya adalah desain program dimana pada tahap ini dibuat desain rancangan sistem menggunakan use case, flowchart, algoritma, dan rancangan layar. Serta membuat perancangan program untuk menfasilitasi fitur-fitur yang dibutuhkan pada aplikasi sales order Tahap pengkodean dilakukan setelah tahap desain program dimana pada tahap ini adalah proses implementasi desain rancangan layar mejadi tampilan form menggunakan bahasa pemograman PHP untuk berbasis web dan pada mobile smartphone menggunakan bahasa pemograman java, serta database yang terhubung menggunakan MariaDB. Tahap terakhir yaitu tahapan Pengujian dimana tahapan melakukan beberapa testing atau pengujian program, baik dengan menggunakan browser maupun perangkat telepon selular berbasis android. Jika masih ada hal yang masih belum berjalan maka akan dilakukan perbaikan baik dari layar maupun program.

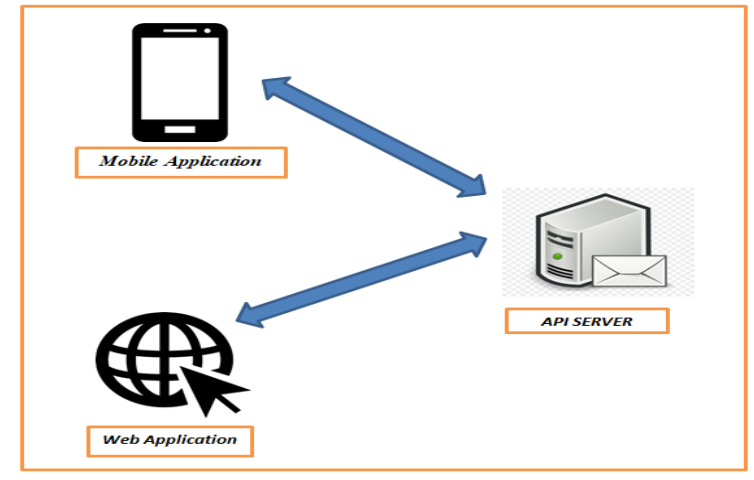

Gambar 2. Aristektur Aplikasi

Pada gambar 2 menunjukkan arsitektur aplikasi yang akan digunakan pada sistem yang akan dibuat. Pada gambar sisi sebelah kiri dapat dilihat bahwa aplikasi client yang akan dibuat terdiri dari aplikasi yang berbasis web, dan aplikasi berbasis mobile. Sedangkan di sisi server aplikasi yang akan dibuat adalah aplikasi web service yang menggunakan arsitektur REST.

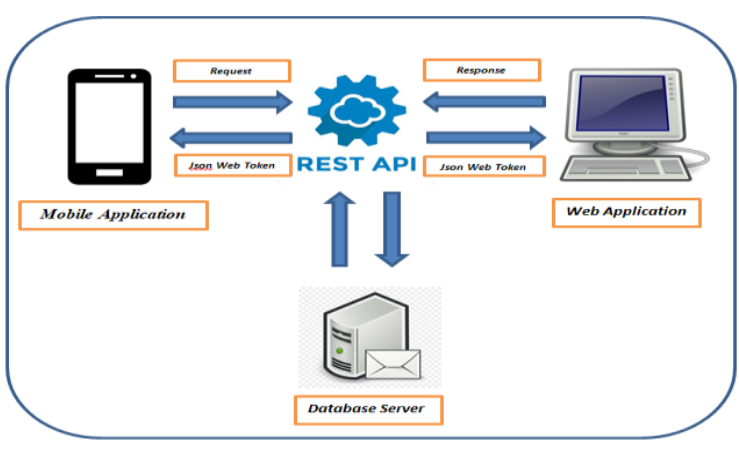

Gambar 3. Arsitektur Sistem

Pada gambar 3 diatas menunjukkan skema pengambilan data menggunakan RESTful API. Data barang yang sudah dipesan oleh pelanggan pada mobileakan dikirimkan dalam bentuk Json Web Token (JWT). Kemudian data tersebut akan dikirim ke server API yang dibangun. Server API akan melakukan proses permintaan ke database melalui web. Yang kemudian hasil dari proses permintaaan akan dikembalikan lagi ke pengguna dalam bentuk json dan diuraikan oleh aplikasi sehingga data hasil proses bisa digunakan dan ditampilkan.

Perancangan layar user pada aplikasi web merupakan tampilan yang berisi semua dash dari halaman utama setelah admin login yang dapat mengakses aplikasi webini.Terdapat beberapa menu tampilan yang bisa digunakan untuk melihat, mengubah, mengganti, dan 
menghapus data baik itu admin maupun produk beserta apa aja yang dijual dan pemesanan barang beserta sales order.Rancangan layar dash utama seperti pada laporan penjualan barang .Tampilan layar form main gambar 4.

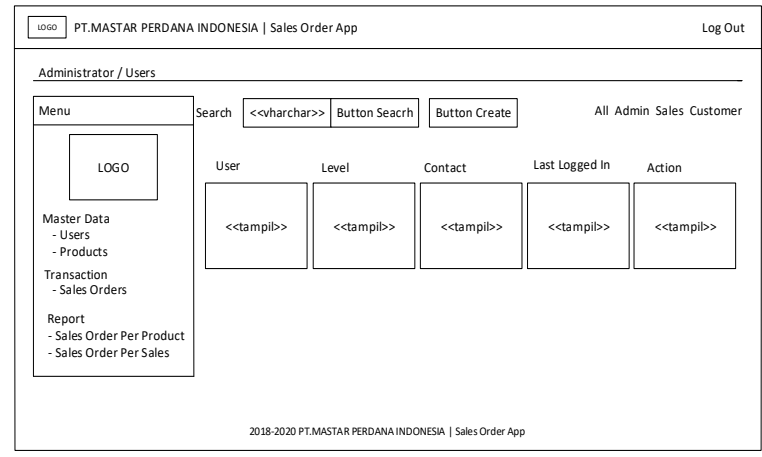

Gambar 4. Rancangan Dash Web

Sedangkan tampilan rancangan pada smartphone untuk sales person dalam mengakses aplikasi ini yang seperti pada gambar 5 .

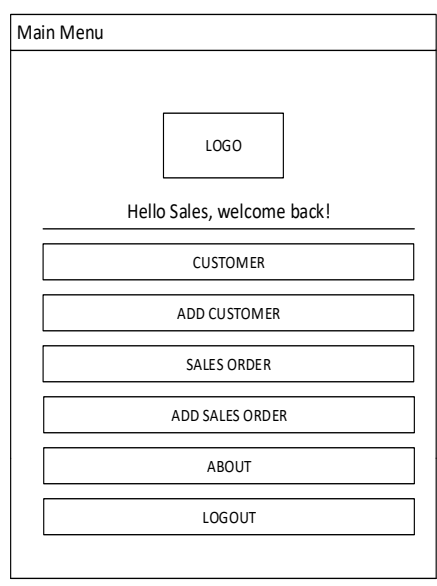

Gambar 5. Rancangan Dash Mobile

\section{Hasil Dan Pembahasan}

Dalam pelaksanaan dan penerapan program yang akan dilakukan dalam perusahaan dibagian penjualan, maka akan dilakukan tindakan untuk mencapai sasaran yang efektif. Didalam pembahasan ini akan dijelaskan mengenai tampilanaplikasi web serviceRESTful API pada web dan android.

Tampilan layar form login merupakan yang pertama person harus melakukan login terlebih dahulu untuk kali muncul saat user ketika membuka aplikasi ini. dapat memgakses ke halaman utama. Tampilan layar Pada tampilan ini user harus melakukan login terlebih form login seperti pada gambar 8.

dahulu untuk dapat memgakses ke halaman utama. Tampilan layar form login seperti pada gambar 6.

Setelah melakukan login maka akan keluar tampilan layar main menu yang merupakan halaman utama dash. Setelah berhasil melakukan proses login maka akan Pada tampilan layar ini akan menampilkan menu-menu keluar tampilan layar halaman utama dash user. Pada pada aplikasi mobile dari melakukan pendataan tampilan layar main menu ini akan menampilkan semua pelanggan baru dan melakukan proses sales order data user baik data sebagai admin, customer maupun pelanggan. Tampilan layar form main menu seperti sales person yang telah terdaftar pada aplikasi. Dan pada gambar 9.

pada tampilan ini juga terdapat halaman produk barang

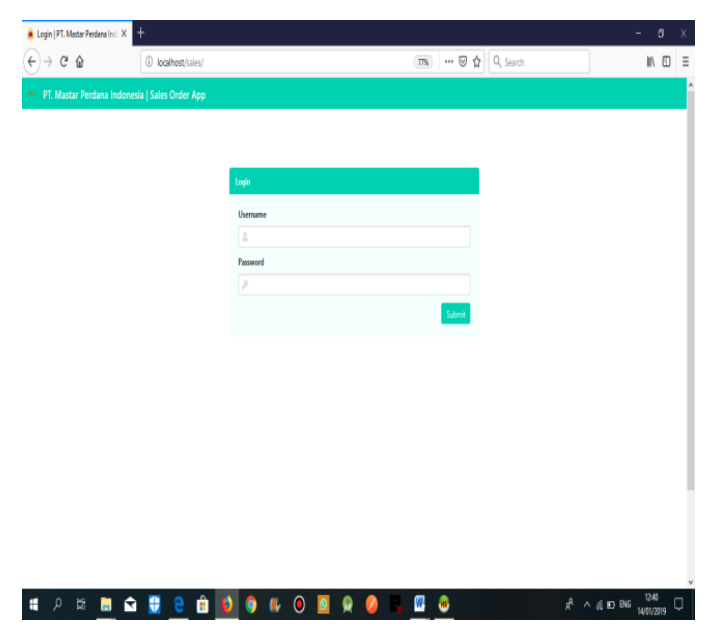

Gambar 6 Tampilan Layar Form Login Aplikasi Web

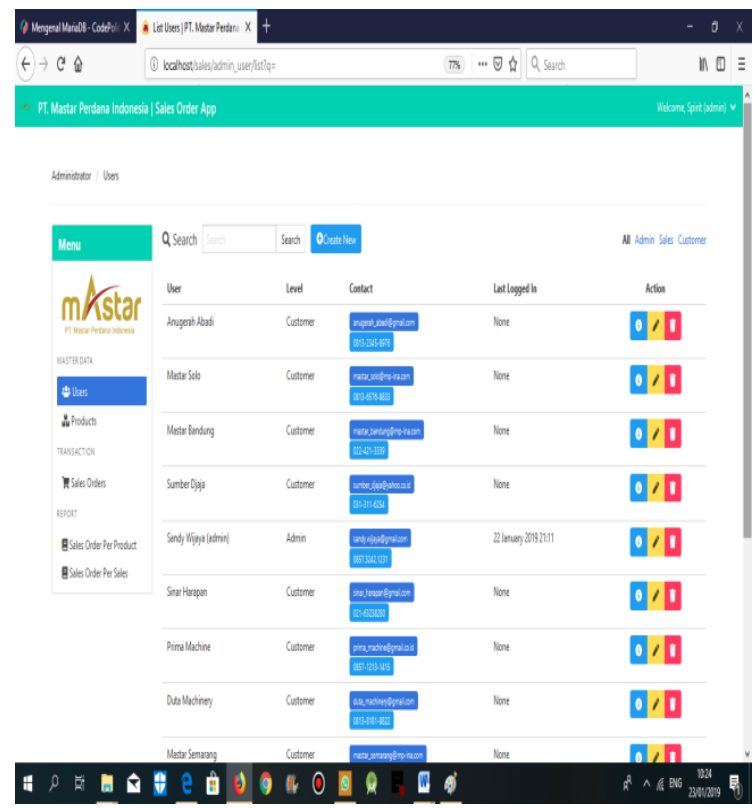

Gambar 7. Tampilan Layar Form Main Menu Aplikasi Web

Untuk aplikasi mobile tampilan layar login merupakan yang pertama kali muncul saat sales person ketika membuka aplikasi mobile.Pada tampilan ini sales 

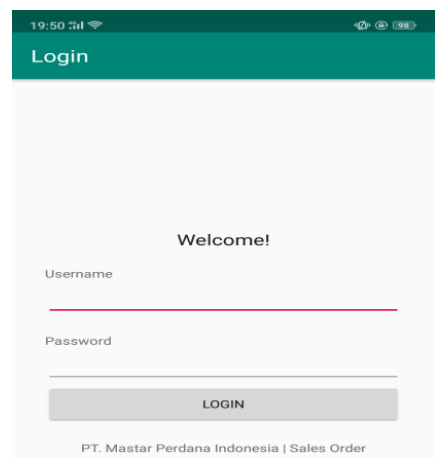

Gambar 8. Tampilan Layar Form Login Pada Mobile
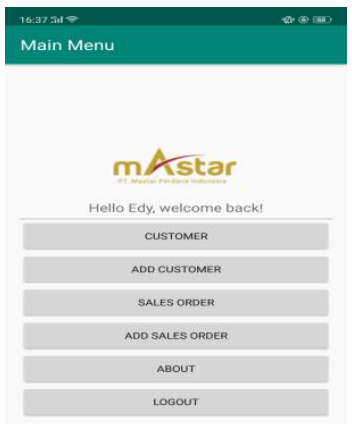

Gambar 9. Tampilan Layar Main MenuAplikasi Mobile

Untuk melakukan testing program RESTful API menggunakan tool yaitu postmanseperti pada gambar 10.Fungsi utama postman ini adalah sebagai GUI API Caller namun sekarang postman juga menyediakan beberapa fitur yaitu Sharing Collection API for Documentation, Testing API, Real Time, Monitoring API, Integrration.



Gambar 10.Tool Postman
Pada saat postman dijalankan yang dilakukan sales person dalam melakukan login dengan menggunakan method POSTmaka akan keluar token untuk membuka tampilan menu pada aplikasi mobile seperti pada gambar 11.

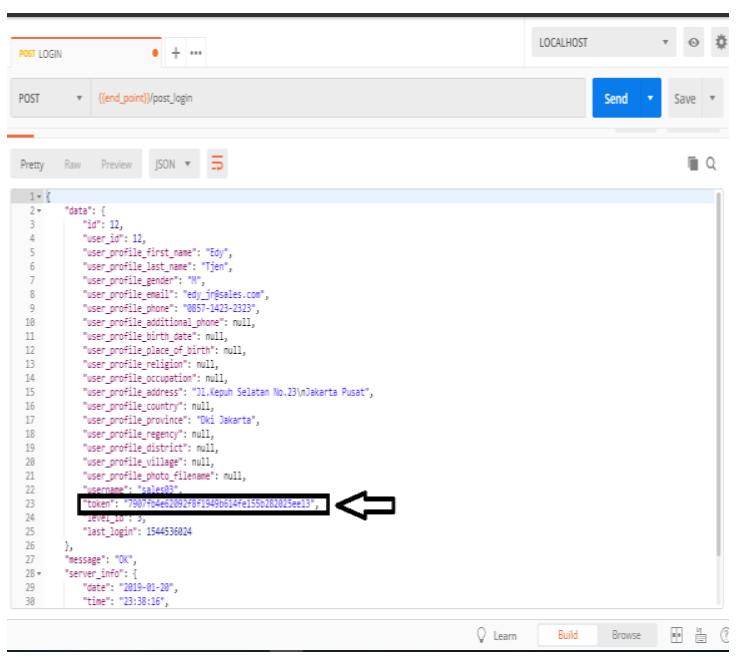

Gambar 11. Tampilan Token Pada Saat Login

Token tersebut akan disimpan oleh user pada local storage dan bila user mengakses halaman tertentu maka harus menyertakan token tersebut. Token tersebut akan dimasukkan ke manage environmentsuntuk melakukan testing pada data yang terdapat di dalam aplikasi pada seperti gambar 12 .

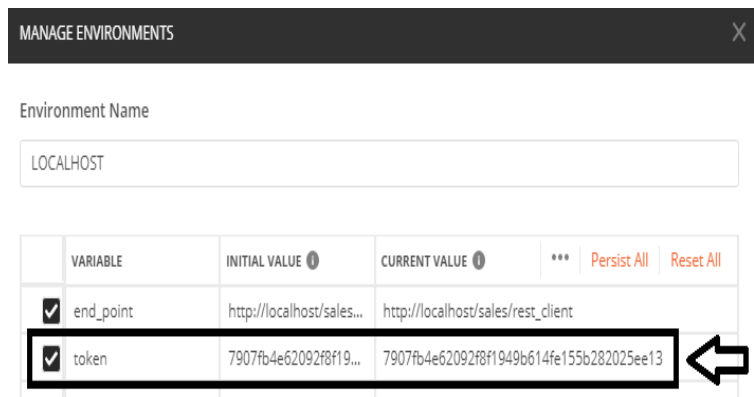

Gambar 12.Tampilan Pengisian Token Dalam Variable

Langkah lanjutan dalam pengujian testing RESTful API adalah memanggil data produk dengan menggunakan method GETyang ditampilkan seperti pada gambar 13 . Diharuskan mengisi url yang akan dipanggil data produk dengan mengisi header dengan token pada saat melakukan login.

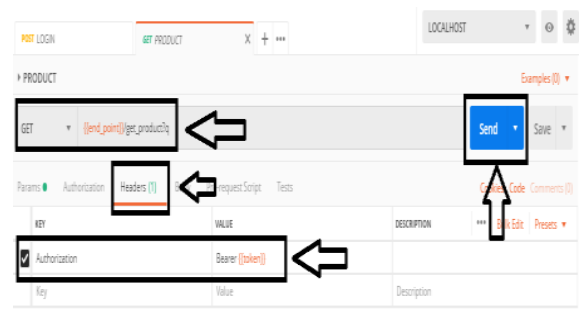

Gambar 13. Tampilan Untuk Memanggil Data Produk

Jurnal RESTI (Rekayasa Sistem dan Teknologi Informasi) Vol. 3 No. 2 (2019) 106 - 112 
Setelah menekan tombol send maka akan keluar pelanggan ada penambahan dalam pemesanan produk, tampilan data produk yang telah dienkripsi oleh json dan status reject jika pelanggan membatalkan order web token, seperti pada gambar 14 . produk.

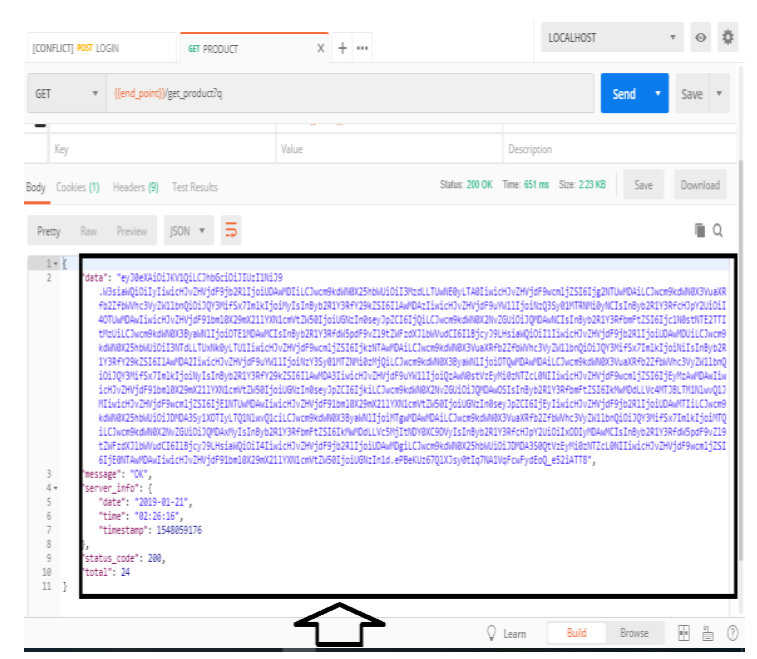

Gambar 14. Tampilan Data Produk Dalam Bentuk JWT

Untuk hasil dekripsi dalam bentuk json web token maka akan keluar data asli barang seperti pada gambar 15 .

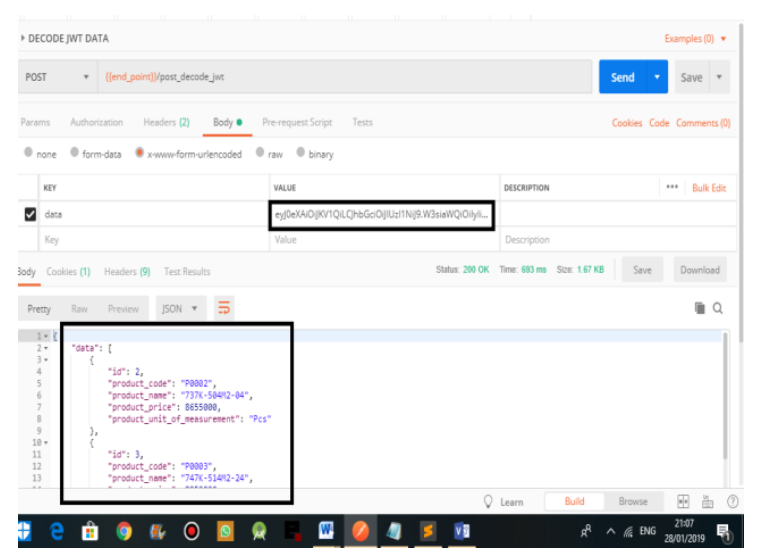

Gambar 15. Tampilan Data Barang Hasil Dekripsi

Uji coba dan evaluasi dilakukan agar dapat melihat hasil, apakah ada kekurangan dalam aplikasi tersebut.

Tabel 1. Login Aplikasi Sales Person

\begin{tabular}{|c|c|c|c|c|c|c|}
\hline $\mathrm{N}_{0}$ & Id & User & Name & Token & Login & is_actired \\
\hline 1 & 2 & Sales01 & Hendy & $7907 \mathrm{fb}-4 \mathrm{e} 2092 \mathrm{fs} 194966614 \mathrm{fe} 155 \mathrm{~b} 282025 \mathrm{ee} 13$ & 09/01/201909:14 & A \\
\hline 2 & 2 & Sales03 & Edy & a26d4c6blba8901545009c7efb4f0ef382518b05 & 09/01/2019 11:11 & $A$ \\
\hline 3 & & Sales05 & Alvian & ff232de78bae102126focb6be3863110549966248 & 09:01201910:13 & A \\
\hline
\end{tabular}

Tabel 1 diatas merupakan aktifitas sales person dalam menggunakan aplikasi mobile.

Tabel 2 di atas merupakan hasil dari sales person dalam menginput data pemesanan produk kepada pelanggan yang akan di proses oleh adminuntuk dibuatkan invoice. Proses sales order sampai tahap pembuatan invoice pada status close.Pada status open, jika
Tabel 2. Hasil Uji Sales Order

\begin{tabular}{|c|c|c|c|c|c|}
\hline No & SO_Code & Customer & Sales_id & Ship_Datetime & Status \\
\hline 1 & 7HMDUVFWW & Duta Machinery & Sales 01 & 09/01/2019 09:30 & Close \\
\hline 2 & FT6P25TVCW & MPI Solo & Sales 03 & $09 / 01 / 201911: 25$ & Close \\
\hline 3 & PXJ7YRW2X3 & MPI Bandung & Sales 05 & 09/01/2019 10:23 & Close \\
\hline 4 & URH2HRRY4R & Sinar Harapan & Sales 03 & 09/01/2019 14:22 & Open \\
\hline 5 & US625EYEZW & Toko Subur & Sales 01 & $09 / 01 / 201911: 28$ & Close \\
\hline 6 & DH6XZYEWU & Anugerah & Sales 03 & 09/01/2019 15:11 & Close \\
\hline 7 & $5 \mathrm{H} 2 \mathrm{TXPHJNT}$ & MPI Semarang & Sales 05 & 09/01/2019 12:19 & Close \\
\hline 8 & GKL30WEPDL & Sinar Jaya & Sales 01 & 09/01/2019 13:09 & Close \\
\hline 9 & PL4ASAF1CV & Cahaya Sewing & Sales 05 & 09/01/2019 12:30 & Reject \\
\hline 10 & 4ERFSADSC 2 & Toko Mentari & Sales 05 & 09/01/2019 13:41 & Close \\
\hline 11 & 9FRASLL3LA & Abadi Perkasa & Sales 03 & 09/01/2019 15:41 & Close \\
\hline 12 & PRIS2SD5AA & Jaya Abadi & Sales 05 & 09/01/2019 14:11 & Close \\
\hline 13 & OPSJDIS23YU & Surya Agung & Sales 01 & 09/01/2019 15:11 & Reject \\
\hline 14 & TS5AQZMDL & Lima Jaya & Sales 05 & 09/01/2019 15:21 & Close \\
\hline 15 & ER2PLEMMZ & KNP Garmindo & Sales 03 & 09/01/2019 16:53 & Open \\
\hline
\end{tabular}

\section{Kesimpulan}

Aplikasi sales order dengan RESTful API ini berjalan baik pada web dan android sehingga proses pemesanan produk menjadi lebih mudah. Penggunaan autentifikasi json web token pada RESTful API ini membuat aplikasi menjadi lebih aman karena aplikasi tidak dapat diakses jika tidak menggunakan token.

\section{Daftar Rujukan}

[1] Kurniawan, E., 2014. Implementasi Rest Web Service Untuk Sales Order Dan Sales Tracking Berbasis Mobile. Eksis, vol. 7, no. 1, pp. 1-12.

[2] Perwira, R.I, Santosa, B., 2017. Implementasi Web Service Pada Integrasi Data Akademik Dengan Replika Pangkalan Data Dikti. Telematika, vol. 14, no. 1, pp. 1-11.

[3] Rulloh dkk, 2017. Implementasi REST API pada Aplikasi Panduan Kepaskibraan Berbasis Android. Tek. Vol. 1 No. 2, vol. 1 , no. 2, pp. 85-89.

[4] Tanaem, P.F., Manongga, D., dan Iriani, A., 2016. RESTFul Web Service Untuk Sistem Pencatatan Transaksi. J. Tek. Inform. dan Sist. Inf., vol. 2, no. April, pp. 2443-2229.

[5] Nurdiyanto, W. , 2012. Perbandingan SOAP dan REST sebagai Web Service [Online]. Available at : http://pusdiklat.bps.go.id/index.php?r=artikel/cetak\&id=206. [Accessed: 21 Feb 2019].

[6] Rahmatulloh,A., Sulastri, H., dan Nugroho, R. 2018. Keamanan RESTful Web Service Menggunakan JSON Web Token (JWT) HMAC SHA-512". J. Nas. Tek. Elektro dan Teknol. Inf., vol. 7, no. 2.

[7] Situmorang, J.D., 2013. Implementasi Algoritma Keyed-Hash Message Authentication Code ( HMAC) Pada Pesan Teks Berbasis Chatting,. Pelita Inform. Budi Darma, vol. III, no. April, pp. 89-95.

[8] Yusmantoro, S., Hermansyah, E., dan Efendi, R., 2014. Pengamanan Keaslian Surat Elgamal Dan Secure Hash Algorithm 256 Studi Kasus: Badan Pelayanan Perizinan Terpadu ( Bppt ) Kota Bengkulu. J. Rekursif, vol. 2, no. 1, pp. 28-36.

[9] Firman, A., Wowor, H., dan Najoan, X.,, 2016. Sistem Informasi Perpustakaan Berbasis Web Application. J. Sist. Inf. Bisnis, vol. 1, no. 2, pp. 66-77.

10] Warman, I., Ramdaniansyah, R., 2019. Analisis Perbandingan Kinerja Query Database Management System (Dbms) Antara Mysq1 5.7.16 Dan Mariadb 10.1. J. Teknoif, vol. 6, no. 1, pp. $32-41$. 